\title{
Impact of Nuclear Interleukin-1 Alpha and EGFR Expression on Recurrence and Survival Outcomes in Oral Squamous Cell Carcinomas
}

\author{
Anand Rajan, ${ }^{1}$ Katherine N. Gibson-Corley ${ }^{(D,},{ }^{1}$ Allen B. Choi, ${ }^{1}$ \\ Georgina K. Ofori-Amanfo, ${ }^{1}$ Patrick Ten Eyck, ${ }^{2}$ Madelyn Espinosa-Cotton, ${ }^{1,3}$ \\ Steven M. Sperry, ${ }^{4,5}$ and Andrean L. Simons ${ }^{1,3,5}$ \\ ${ }^{1}$ Department of Pathology, University of Iowa Hospitals and Clinics, Iowa City, IA 52242, USA \\ ${ }^{2}$ Institute for Clinical and Translational Science, University of Iowa Hospitals and Clinics, Iowa City, IA 52242, USA \\ ${ }^{3}$ Free Radical and Radiation Biology Program, Department of Radiation Oncology, University of Iowa Hospitals and Clinics, \\ Iowa City, IA 52242, USA \\ ${ }^{4}$ Department of Otolaryngology-Head and Neck Surgery, University of Iowa Hospitals and Clinics, Iowa City, IA 52242, USA \\ ${ }^{5}$ Holden Comprehensive Cancer Center, University of Iowa Hospitals and Clinics, Iowa City, IA 52242, USA
}

Correspondence should be addressed to Andrean L. Simons; andrean-simons@uiowa.edu

Anand Rajan and Katherine N. Gibson-Corley contributed equally to this work.

Received 4 October 2018; Revised 4 May 2019; Accepted 27 May 2019; Published 19 June 2019

Academic Editor: Shinji Miwa

Copyright (C) 2019 Anand Rajan et al. This is an open access article distributed under the Creative Commons Attribution License, which permits unrestricted use, distribution, and reproduction in any medium, provided the original work is properly cited.

Interleukin-1 alpha (IL-1 $\alpha$ ) is a pleiotropic cytokine involved in inflammation and immune response and is upregulated in many solid tumors including head and neck squamous cell carcinomas. Although IL-1 $\alpha$ expression is generally associated with poor prognosis, the implications of the subcellular localization of IL- $1 \alpha$ expression in patient outcomes are poorly understood. This study is aimed at investigating the prognostic value of nuclear and cytoplasmic immunohistochemical IL- $1 \alpha$ expression in oral squamous cell carcinomas (OSCCs). Tissue microarrays containing 146 OSCCs were analyzed for IL- $1 \alpha$ and epidermal growth factor receptor (EGFR) expression by immunohistochemistry. IL-1 $\alpha$ and EGFR expression scores were correlated with clinicopathological parameters and survival outcomes. IL- $1 \alpha$ expression was observed in the nuclear and/or cytoplasmic compartments in $98 \%$ of evaluable tumors and $78 \%$ of tumors expressed IL- $1 \alpha$ in both compartments. There were no differences observed in overall survival or progression-free survival between high, moderate, or negative IL-1 $\alpha$ nuclear/cytoplasmic expression scores. When IL$1 \alpha$ nuclear/cytoplasmic expression scores were stratified by positive or negative EGFR expression, tumors with a combined EGFRpositive and high nuclear IL- $1 \alpha$ expression profile were significantly more likely to possess perineural invasion and were significantly associated with a high risk of tumor recurrence and worse progression-free survival compared to all other EGFR and combined IL- $1 \alpha /$ EGFR expression profiles. Altogether, nuclear IL-1 $\alpha$ expression may enhance the prognostic value of EGFR in OSCC and warrants further study as a prognostic biomarker for recurrence.

\section{Introduction}

The IL-1 pathway plays a plays a critical role in the regulation of immune and inflammatory responses to infections and sterile insults [1]. IL-1 signaling is also frequently upregulated in many solid tumor types including head and neck squamous cell carcinomas (HNSCCs) [2]. Although increased
IL-1 signaling is typically associated with poor prognosis in cancer patients [3-5], the role of IL-1 signaling in cancer is controversial since IL-1 plays roles in both tumor promotion via the expression of genes involved in tumor survival, angiogenesis, metastasis, and immune cell recruitment [6-8] and tumor suppression via increased natural killer (NK) cell activity and enhanced Th1-mediated immunity $[9,10]$. 
The IL-1 pathway is triggered when the ligands IL$1 \alpha$ and IL- $1 \beta$ bind to IL- 1 receptor type I (IL-1R1). Upon ligand binding, the receptor forms a heterodimer with IL1 receptor accessory protein (IL-1RAcP), which leads to the recruitment of the cytosolic coadaptor protein myeloid differentiation primary response gene 88 (MyD88) via its toll-like-interleukin-1 receptor (TIR) domain, followed by recruitment of IL-1 receptor-associated kinases and TNF Receptor Associated Factor 6 (TRAF6) [11]. These signaling events activate nuclear factor kappa-light-chain-enhancer of activated B cells (NFkB) and mitogen-activated protein kinases (MAPK) signaling leading to the expression of IL-1 target genes including activating IL- 1 ligands (IL- $1 \alpha$ and IL$1 \beta$ ) which activate and reinforce a positive feed-forward loop and sustained release of cytokines [11].

Of the activating ligands in the IL- 1 family, IL- $1 \beta$ is the most studied. IL- $1 \beta$ is initially translated into an immature pro-IL- $1 \beta$ and cleaved into its active form by caspase- 1 and released from the cell [11]. IL- $1 \alpha$ is less studied and has a different biological role than IL- $1 \beta$. IL- $1 \alpha$ also exists as a precursor (pro-IL- $1 \alpha$ ) and can be cleaved by the calciumactivated neutral protease calpain into a $17-\mathrm{kDa}$ C-terminal component, known as "mature" IL- $1 \alpha$, and a $16-\mathrm{kDa} \mathrm{N}$ terminal propiece (ppIL-1 $\alpha$ ) [12]. Both pro-IL- $1 \alpha$ and the mature IL- $1 \alpha$ are active and are able to bind to IL-1R1 and trigger signaling [12]. Pro-IL- $\alpha$ also contains a nuclear localization signal (NLS) not present in the mature form, which is retained in the ppIL- $1 \alpha$ after cleavage of pro-IL- $1 \alpha$ [13]. This allows both pro-IL- $1 \alpha$ and ppIL- $\alpha$ to translocate to the nucleus. Nuclear localization of IL- $1 \alpha$ (i.e., pro-IL- $1 \alpha$ and ppIL- $1 \alpha$ ) is believed to be functionally important, due to the ability of these entities to bind DNA [14] and activate NFkB and specificity protein 1 (Spl) which play important roles in cell proliferation [15].

Previous work has shown that HNSCC tumors have increased mRNA expression levels of IL- $1 \alpha$ and IL- $1 \beta$ compared to adjacent normal tissue [6] and that tumors with high IL- $1 \alpha$ gene expression and protein secretion are associated with the development of distant metastasis in HNSCC patients [5]. Despite these previous observations, little is known about the in situ tumor expression of IL$1 \alpha$ in HNSCCs, the subcellular distribution of IL- $1 \alpha$ in HNSCC tumors, and the prognostic significance of IL$1 \alpha$ localization in HNSCC patients. Additionally, EGFR is well known as a prognostic marker in HNSCC [16] and a crosstalk relationship has been previously reported between the EGFR and IL-1 pathways $[17,18]$. The goals of this study are to (1) characterize the subcellular distribution of IL- $1 \alpha$ in OSCCs and (2) determine the prognostic significance of IL- $1 \alpha$ subcellular localization and combined EGFR/IL- $1 \alpha$ expression in OSCC patients.

\section{Materials and Methods}

2.1. Tissue Microarrays (TMAs). Formalin-fixed paraffinembedded tumor samples of patients were obtained from the archives of the Department of Pathology at the University of Iowa Hospitals and Clinics. TMAs were constructed using 3-6 morphologically representative tumor regions $(1 \mathrm{~mm})$ chosen from 146 carcinomas from the oral cavity. The 146 cases were surgical resection specimens and chosen selectively to ensure a mixture of patients with and without recurrence, with and without node metastases or positive margins, young and old ages, and smokers and nonsmokers from a population of 421 patients spanning 10 years of time (2005-2014). After generating a list of 266 patients proposed for inclusion in the TMA, only 146 were included in the TMA block construction due to paraffin-embedded formalin-fixed tissue block availability and quality and resource constraints. Chi-square analysis of the $\mathrm{T}$ stage distribution of the patients in the larger database (T1/T2/T3\&4: 31/29/39\%) showed no statistically significant difference from the patient cohort included in the study (29/29/40\%). None of the patients included in the TMA underwent prior radiation or chemotherapy. Four $\mu \mathrm{m}$ sections were obtained from the TMAs on poly-L-lysinecoated glass slides. Routine hematoxylin and eosin (H\&E) sections were reviewed to confirm the original diagnosis.

2.2. Immunohistochemistry (IHC). Antigen retrieval was performed on freshly cut sections in a decloaking chamber for 5 min at $125^{\circ} \mathrm{C}$ in TRIS buffer ( $\mathrm{pH} 9.0$ ). Endogenous peroxidase was blocked by incubation with $3 \%$ peroxide at room temperature for $2 \mathrm{~min}$. For IL- $1 \alpha$ staining, human specific IL- $1 \alpha$ antibody (ab9614, Abcam) was applied at 1:250 in Dako diluent for $2 \mathrm{~h}$ at room temperature. The peptide sequence used to raise this antibody is SAPFSFLSNVKYNFMRIIKYEFILNDALNQSIIRANDQYLTAAALHNLDEAVKFDMGAYKSSKDDAKITVILRISKTQLYVTAQDEDQPVLLKEMPEIPKTITGSETNLLFFWETHGTKNYFTSVAHPNLFIATKQDYWVCLAGGPPSITDFQILENQA (amino acids 113-271) and therefore recognizes both full length/pro-IL-1 $\alpha$ (amino acids 1-271) and mature IL- $\alpha$ (amino acids 113-271). EGFR immunostaining was performed with antibody (H11, Dako) at 1:200 dilution. Bound antibody was detected using Envison ${ }^{\mathrm{TM}}$ + HRP, rabbit (Dako North America) for $30 \mathrm{~min}$ at room temperature followed by incubation with diaminobenzidine substrate $(\mathrm{DAB})$ for $5 \mathrm{~min}$ at room temperature. HPV status was determined by p16 expression $[19,20]$. After completion of IHC, slides were stored at room temperature and a virtual scanned copy of the TMA slides was kept for further reference.

2.3. Quantification of $I L-1 \alpha$ and EGFR Staining. IL- $1 \alpha$ immunoreactivity was evaluated by KGC using an Olympus BX53 microscope with an Olympus DP72 camera. Human kidney and spleen were used as positive and negative controls for IL-1 $\alpha$ expression, respectively. Given that IL- $1 \alpha$ expression varied in both the nuclei and cytoplasm, IL- $1 \alpha$ expression was scored separately for the nuclei $(\mathrm{N})$ and cytoplasm $(\mathrm{C})$ on a scale from 0 to 2 , with 0 representing no staining, 1 low/weak staining, and 2 strong/intense staining. The percentage of tumor cells with positive staining was determined by scoring 10 microscopic fields of 100 tumor cells each. Quantitative evaluation of EGFR staining was performed by AR according to Gamboa-Domingez et al. and Modern Pathology, 2004 [21], using a semiquantitative score $(0-3+)$ where 0 represents 
no staining or membranous positivity in $<10 \%$ neoplastic cells (negative) and 1,2, and 3 represent weak, moderate, and strong membranous immunopositivity in $>10 \%$ neoplastic cells.

2.4. Statistical Analysis. The associations between IL- $1 \alpha$ and/or EGFR expression with clinicopathological features such as sex, age, smoking history, tumor site, pathological TNM classification (UICC 7th), differentiation (well/moderately/poor), perineural, lymphovascular, and bone invasion were tested using the generalized linear modeling (GLM) framework and the Kruskal-Wallis test. Differences in survival outcomes (overall survival [OS] and progression-free survival [PFS]) were plotted using the Kaplan-Meier method while estimates for the group hazard ratios were obtained using Cox proportional hazards ( $\mathrm{PH})$ modeling. OS is defined as the length of time from the date of diagnosis that the patients remain alive. PFS is defined as the time from diagnosis to disease progression or death from any cause. All testing was performed on the univariate level and unadjusted for multiple comparisons. Differences between survival curves were compared using the log-rank test. A $p$-value below 0.05 was considered statistically significant. All analyses were completed using SAS 9.4.

\section{Results}

3.1. Patient Characteristics. A total of 146 patient samples were included in the OSCC TMA, of which 141 showed interpretable IL-1 $\alpha$ and EGFR immunostaining. Reasons for lost samples included loss/absence of tissue in the TMA section during IHC processing. The baseline characteristics for these patients are summarized in Table 1. Of the 141 patients, 82 patients were males with an average age of diagnosis of 58 years, and 59 patients were female with an average age of diagnosis of 66 years (Table 1). Smoking histories were reported in most patients with $56(40 \%)$ active smokers, 13 (9\%) that had quit smoking for less than 10 years, $17(12 \%)$ that quit smoking for more than 10 years, and $6(4.3 \%)$ tobacco chewers (Table 1$)$. Males made up the majority $(78 \%)$ of the active smokers and females made up the majority of the patients with no smoking history (68\%, (data not shown)). Majority of tumor sites represented in the TMA were from the oral tongue, N0 (52\%), and moderately differentiated (64\%) (Table 1). Approximately 78 (55\%) patients received adjuvant radiotherapy and $22(16 \%)$ patients received chemotherapy following surgery (Table 1). Only 5 of the evaluable tumors were HPV-positive as detected by p16 expression (data not shown).

3.2. IL-1 $\alpha$ Expression. IL- $1 \alpha$ expression was detected in the cytoplasm and/or nucleus in at least 1 of 3-6 cores for the vast majority of patients (98\%). Examples of IHC images of primarily nuclear, primarily cytoplasmic and combined nuclear/cytoplasmic IL- $1 \alpha$ immunoreactivity are shown in Figures 1(a)-1(c), respectively. Combined nuclear/cytoplasmic IL- $1 \alpha$ scores were generated for each patient based on the intensity (negative [0], moderate [1], and strong [2]) of IL- $1 \alpha$ staining in each compartment. Tumors were assigned IL-1 $\alpha$ nuclear/cytoplasmic (N/C) expression profile scores including $0 / 0$ : negative nuclear and cytoplasmic IL-1 $\alpha$ expression (Figure 1(d)); 1/0: moderate nuclear and negative cytoplasmic IL-1 $\alpha$ expression (Figure 1(e)); 0/1: negative nuclear and moderate cytoplasmic IL- $1 \alpha$ expression (Figure 1(f)); 1/1: moderate nuclear and cytoplasmic IL-1 $\alpha$ expression (Figure $1(\mathrm{~g})$ ); 1/2: moderate nuclear and strong cytoplasmic IL-1 $\alpha$ expression (Figure 1(h)); and 2/1: strong nuclear and moderate cytoplasmic IL- $1 \alpha$ expression (Figure 1(i)). An IL-1 $\alpha$ expression profile of $1 / 1$ represented the majority $(n=81,[58 \%])$ of tumors in the TMA (Table 2).

3.3. Correlation of IL-1 $\alpha$ Expression with Clinicopathologic Parameters. There were no differences in nuclear or cytoplasmic IL- $1 \alpha$ expression scores based on sex or age (Table 1). However significant differences in both nuclear and cytoplasmic IL- $1 \alpha$ expression cores were observed based on smoking history, tumor site, $\mathrm{T}$ stage, $\mathrm{N}$ stage (cytoplasmic only), differentiation, perineural and lymphovascular invasion (cytoplasmic only), bone invasion, and the number of patients that received radiotherapy or chemotherapy (Table 1 ). There were not enough HPV-positive tumors to assess differences in IL$1 \alpha$ expression. Since the IL- $1 \alpha$ expression profiles $1 / 1,2 / 1$, and $1 / 0$ represented the majority of tumors in the TMA (Table 2 ), we further analyzed the association of these expression profiles with clinicopathological features of the represented OSCC patients. We found no differences in overall survival $(p=0.27)$ or progression-free survival $(p=0.29)$ with respect to these 3 major IL-1 $\alpha$ expression profiles (Figures 2(a) and $2(\mathrm{~b}))$.

3.4. EGFR Expression. We next examined the role of EGFR expression in survival outcomes in OSCC patients. Examples of EGFR expression scores are shown in Figure 3. EGFR expression was observed in $61 \%$ of the tumors with strong (score of 3 ) expression in $34 \%$, moderate (score of 2 ) expression in $16 \%$, low (score of 1 ) expression in $11 \%$, and no (score of 0 ) expression in of 39\% of tumors (Table 3). There were no differences observed in overall survival $(p=0.69)$ according to EGFR scores (Figure 4(a)); however significant differences were observed in progression-free survival $(p=0.04)$ with higher EGFR expression being associated with worse progression-free survival (Figure 4(b)). A comparison of combined strong (3)+moderate (2) EGFR (designated as EGFR+) expression and combined low (1)+no (0) EGFR (designated as EGFR-) expression also showed a significant difference in progression-free survival $(p=0.02)$ (Figure $4(\mathrm{~d})$ ) but not overall survival $(p=0.22)$ (Figure $4(c))$. These results support prior reports that EGFR expression is a strong predictor of progression-free survival in HNSCC patients $[16,22]$.

3.5. Correlation of Combined EGFR and IL-1 $\alpha$ with Patient Outcomes. We next evaluated if differences in nuclear/ cytoplasmic IL-1 $\alpha$ expression scores altered the predictive value of EGFR. There were no significant differences $(p=0.31)$ in EGFR expression in tumors with $1 / 0,1 / 1$, and 
TABLE 1: Patient characteristics by IL-1 $\alpha$ Immunostaining.

\begin{tabular}{|c|c|c|c|c|c|c|c|c|c|}
\hline \multirow[b]{2}{*}{ Characteristics } & \multirow[b]{2}{*}{ Total (n) } & \multicolumn{3}{|c|}{ Nuclear IL-1 $\alpha *$} & \multicolumn{5}{|c|}{ Cytoplasmic IL-1 $\alpha *$} \\
\hline & & $2(\%)$ & $1(\%)$ & $0(\%)$ & $p$-value & $2(\%)$ & $1(\%)$ & $0(\%)$ & $p$-value \\
\hline Number of Evaluable & 141 & & & & & & & & \\
\hline Subjects & & & & & & & & & \\
\hline \multicolumn{10}{|l|}{ Sex } \\
\hline Male & 82 & 57 & 58 & 57 & \multirow{2}{*}{0.99} & 50 & 58 & 59 & \multirow{2}{*}{0.37} \\
\hline Female & 59 & 43 & 42 & 43 & & 50 & 42 & 41 & \\
\hline \multicolumn{10}{|l|}{ Avg Age at Diagnosis } \\
\hline Male & 58 & 59 & 58 & 54 & \multirow{4}{*}{0.74} & 53 & 57 & 62 & \multirow{4}{*}{0.28} \\
\hline (avg (range)) & $(31-81)$ & $(37-76)$ & $(31-81)$ & $(44-69)$ & & & $(31-81)$ & $(37-73)$ & \\
\hline Female & 66 & 58 & 68 & 63 & & 78 & 67 & 61 & \\
\hline (avg (range)) & $(19-33)$ & $(19-81)$ & $(20-93)$ & $(58-73)$ & & & $(19-93)$ & $(44-80)$ & \\
\hline \multicolumn{10}{|l|}{ Smoking History } \\
\hline Active Smoker & 56 & 36 & 42 & 29 & \multirow{5}{*}{$<0.0001$} & 0 & 39 & 44 & \multirow{5}{*}{$<0.0001$} \\
\hline Never Smoker & 49 & 29 & 38 & 14 & & 100 & 34 & 33 & \\
\hline Quit $<10$ Years & 13 & 14 & 7 & 29 & & 0 & 9 & 11 & \\
\hline Quit $>10$ Years & 17 & 11 & 11 & 29 & & 0 & 13 & 11 & \\
\hline Tobacco Chewer & 6 & 11 & 3 & 0 & & 0 & 5 & 0 & \\
\hline \multicolumn{10}{|l|}{ Tumor Site } \\
\hline Alveolus & 21 & 7 & 18 & 0 & \multirow{4}{*}{$<0.0001$} & 50 & 13 & 19 & \multirow{4}{*}{$<0.0001$} \\
\hline Floor of the Mouth & 31 & 18 & 23 & 29 & & 0 & 17 & 44 & \\
\hline Oral Tongue & 54 & 46 & 37 & 29 & & 0 & 44 & 19 & \\
\hline Other & 35 & 29 & 23 & 43 & & 50 & 26 & 19 & \\
\hline \multicolumn{10}{|l|}{ T Stage } \\
\hline $\mathrm{T} 1$ & 42 & 36 & 29 & 14 & \multirow{3}{*}{0.001} & 50 & 30 & 26 & \multirow{3}{*}{$<0.00001$} \\
\hline $\mathrm{T} 2$ & 42 & 36 & 28 & 29 & & 0 & 30 & 30 & \\
\hline T3/T4 & 57 & 29 & 42 & 57 & & 50 & 39 & 44 & \\
\hline N Stage & & & & & & & & & \\
\hline No & 74 & 43 & 56 & 43 & & 50 & 54 & 48 & \\
\hline $\mathrm{N} 1 / 2 \mathrm{a}$ & 27 & 29 & 16 & 29 & 0.137 & 0 & 16 & 33 & $<0.00001$ \\
\hline $\mathrm{N} 2 \mathrm{~b} / 2 \mathrm{c} / 3$ & 40 & 29 & 28 & 29 & & 50 & 30 & 19 & \\
\hline Differentiation & & & & & & & & & \\
\hline well & 17 & 7 & 13 & 14 & & 0 & 13 & 7 & \\
\hline moderate & 90 & 75 & 62 & 43 & $<0.001$ & 50 & 64 & 63 & $<0.0001$ \\
\hline poor & 34 & 18 & 25 & 43 & & 50 & 22 & 30 & \\
\hline Perineural Invasion & & & & & & & & & \\
\hline Yes & 69 & 61 & 45 & 57 & 0.06 & 0 & 50 & 48 & $<0.001$ \\
\hline No & 72 & 39 & 55 & 43 & & 100 & 50 & 52 & \\
\hline Lymphovascular Invas & & & & & & & & & \\
\hline Yes & 52 & 43 & 35 & 43 & 0.41 & 50 & 39 & 26 & 0.002 \\
\hline No & 89 & 57 & 65 & 57 & & 50 & 61 & 74 & \\
\hline Bone Invasion & & & & & & & & & \\
\hline Yes & 42 & 21 & 68 & 29 & $<0.001$ & 50 & 29 & 30 & 0.002 \\
\hline No & 99 & 79 & 32 & 71 & $<0.001$ & 50 & 71 & 70 & 0.002 \\
\hline Radiotherapy & & & & & & & & & \\
\hline Yes & 78 & 57 & 54 & 71 & 0.032 & 100 & 53 & 63 & $<0.00001$ \\
\hline No & 63 & 43 & 46 & 29 & & 0 & 47 & 37 & \\
\hline Chemotherapy & & & & & & & & & \\
\hline Yes & 22 & 14 & 15 & 29 & 0.011 & 50 & 15 & 15 & $<0.00001$ \\
\hline No & 119 & 86 & 85 & 71 & & 50 & 85 & 85 & \\
\hline
\end{tabular}

* Percentages may not sum to $100 \%$ due to rounding. 


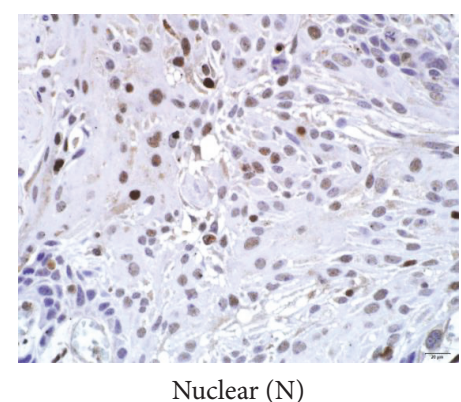

(a)

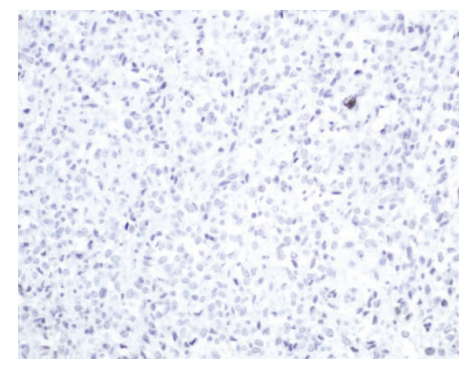

$0 / 0$

(d)

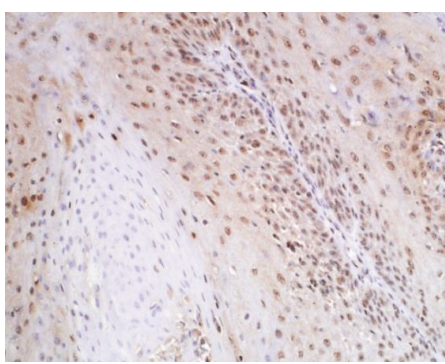

$1 / 1$

(g)

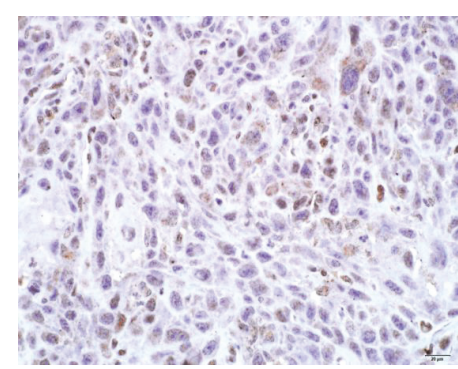

Cytoplasmic (C)

(b)

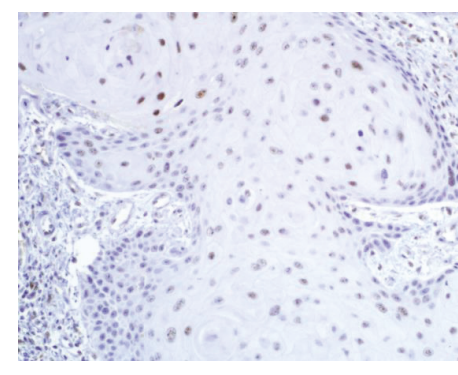

$1 / 0$

(e)

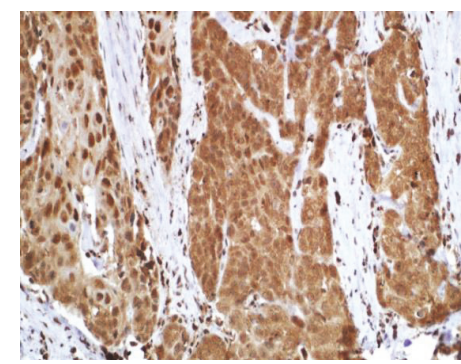

$1 / 2$

(h)

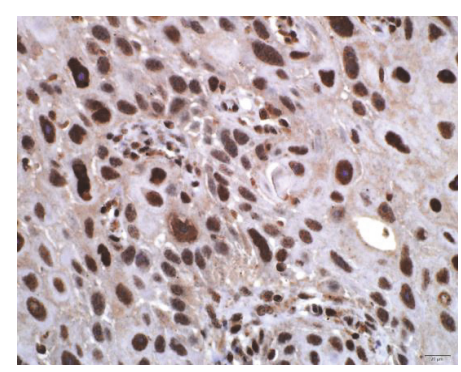

Nuclear \& Cytoplasmic (N/C)

(c)

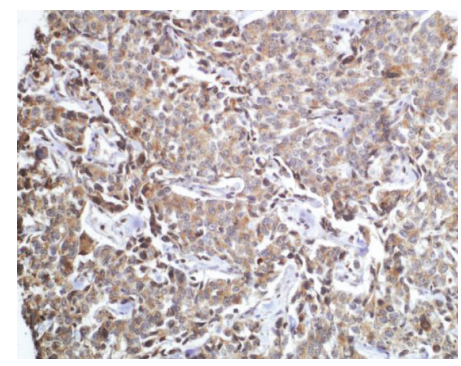

$0 / 1$

(f)

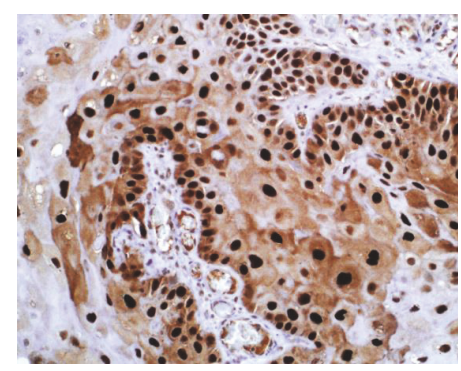

$2 / 1$

(i)

FIGURE 1: Representative examples of nuclear and cytoplasmic IL-1 $\alpha$ immunostaining in OSCC and expression scores. (a) IL-1 $\alpha$ expression in the nuclei; (b) IL-1 $\alpha$ expression in the cytoplasm; and (c) IL-1 $\alpha$ in both the nuclei and cytoplasm. (d) negative nuclear and cytoplasmic IL-1 $\alpha$ expression; (e) moderate nuclear and negative cytoplasmic IL-1 $\alpha$ expression; (f) negative nuclear and moderate cytoplasmic IL-1 $\alpha$ expression; (g) moderate nuclear and cytoplasmic IL-1 $\alpha$ expression; (h) moderate nuclear and strong cytoplasmic IL-1 $\alpha$ expression; (i) strong nuclear and moderate cytoplasmic IL- $1 \alpha$ expression. N: nuclear; C: cytoplasmic.

2/1 IL-1 $\alpha$ expression profiles (Figure 5(a)). Tumors with a high nuclear/moderate cytoplasmic IL-1 $\alpha$ expression profile (2/1) combined with a moderate/strong (2/3) EGFR expression score, which was designated as $2 / 1 / E G F R+$, were significantly $(p=0.0058)$ more likely to experience tumor recurrence compared to the other IL-1 $\alpha /$ EGFR expression profiles (Figure $5(\mathrm{~b})$ ). We also found a significant interaction $(\mathrm{p}=0.02)$ between the $2 / 1$ IL- $1 \alpha$ profile score and EGFR+ expression (Figure 5(b)) suggesting that this particular 2/1/EGFR+ expression profile could be considered a predictor of tumor recurrence. The high rates of recurrences observed in 2/1/EGFR+ tumors encompassed local, regional, and distant sites alone and in combination (Figure 5(c)). Additionally, 2/1/EGFR+ tumors displayed significantly higher rates of perineural invasion $(p<0.0001)$ compared to the other IL-1 $\alpha /$ EGFR expression profiles (Figure 6(a)). There were no differences among the IL-1 $\alpha /$ EGFR expression profiles with respect to lymphovascular invasion (Figure 6(b)) and bone invasion (Figure 6(c)).

Lastly, we found that patients with 2/1/EGFR+ tumors trended toward worse overall survival compared to 2/1/EGFR- tumors although this association did not reach statistically significance $(p=0.06)$ (Figure $7(a))$. However, 2/1/EGFR+ tumors were significantly associated with worse progression-free survival compared to 2/1/EGFR- tumors $(p<0.0001)$ (Figure $7(\mathrm{~b}))$. EGFR expression did not affect survival outcomes in $1 / 1$ (Figures $7(\mathrm{c})$ and $7(\mathrm{~d})$ ) or $1 / 0$ tumors (Figures $7(\mathrm{e})$ and $7(\mathrm{f}))$. Compared to patients with an overall EGFR- expression profile (median survival $=61.4$ months, Figure 4(d)), patients specifically with 2/1/EGFRtumors appeared to have the most favorable progression-free 


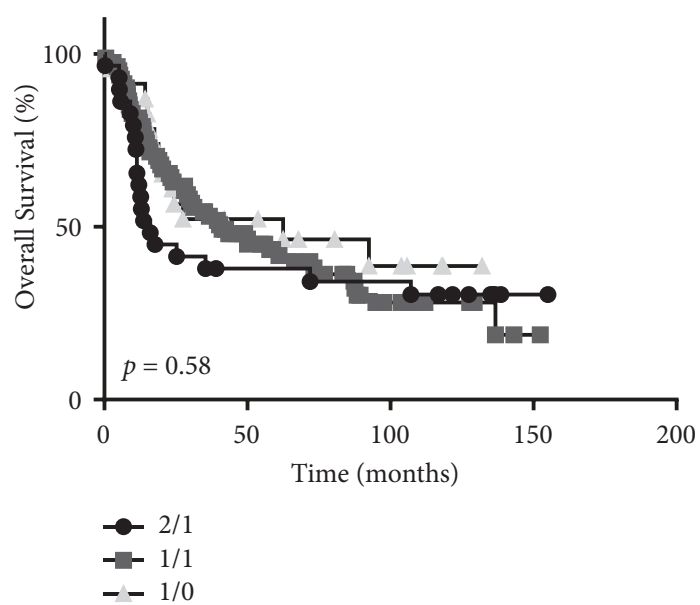

(a)

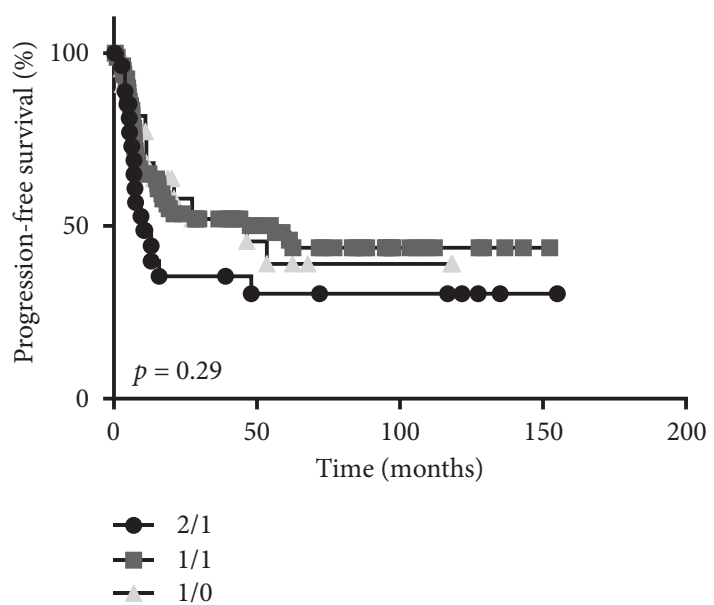

(b)

Figure 2: Prognostic impact by IL-1 $\alpha$ expression score. Shown are Kaplan-Meier estimates of overall survival (a) and disease-free survival (b) according to IL- $1 \alpha$ expression score.
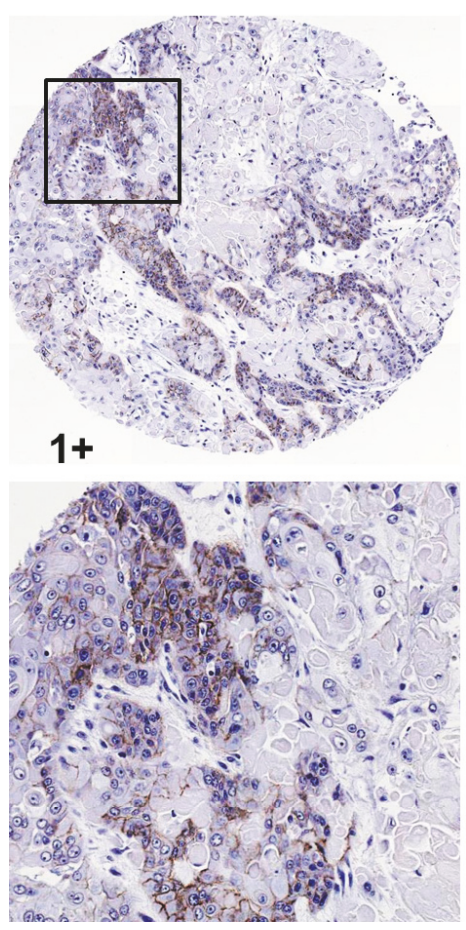

$1+(>10 \%$ tumor, membranous $)$
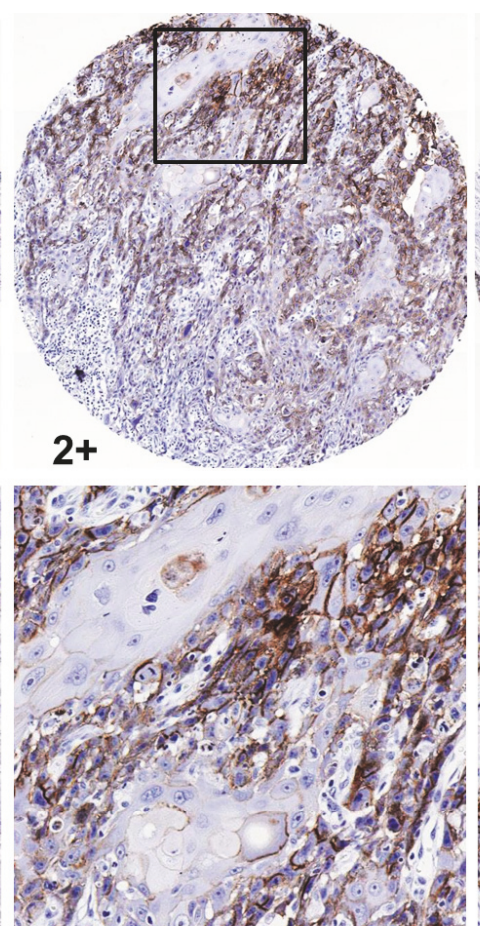

$2+(>10 \%$ tumor, membranous, moderate intensity)

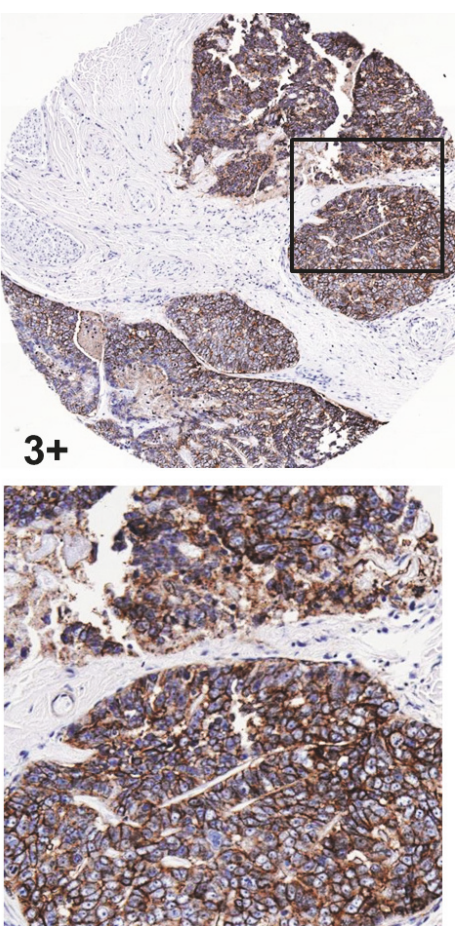

$3+(>10 \%$ tumor, membranous, strongly positive)

FIGURE 3: Representative examples of EGFR immunostaining and expression scores in OSCCs.

survival outcome (median survival=not reached) out of all of the other profiles (Figure 7(b)). Furthermore, we confirmed in Table 4 that adjuvant chemotherapy and/or radiation treatment did not influence the differences in progressionfree survival observed with 2/1/EGFR+ versus 2/1/EGFRtumors (Figure $7(\mathrm{~b})$ ). Altogether, these data suggest that high nuclear IL-1 $\alpha$ expression in combination with moderate/high EGFR expression may be associated with worse outcomes in OSCC patients.

\section{Discussion}

The results from this study imply that nuclear IL- $1 \alpha$ expression may enhance the prognostic value of EGFR with respect to progression-free survival. EGFR is already well known as a prognostic indicator in HNSCCs; therefore the question remains of what role does nuclear IL- $1 \alpha$ play in EGFR signaling? IL-1 $\alpha$ has been reported to be associated with poor prognosis in a wide range of cancers [7, 23-26]. In HNSCCs, 


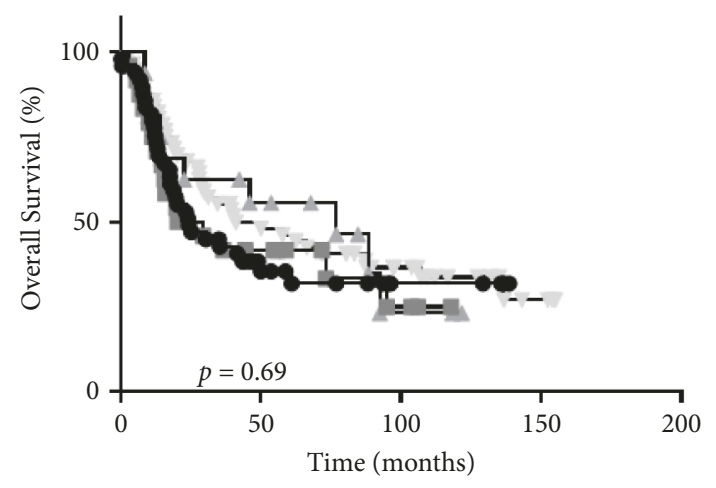

Median Survival (months)

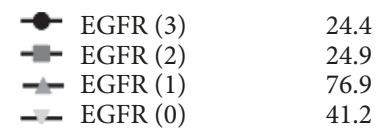

(a)

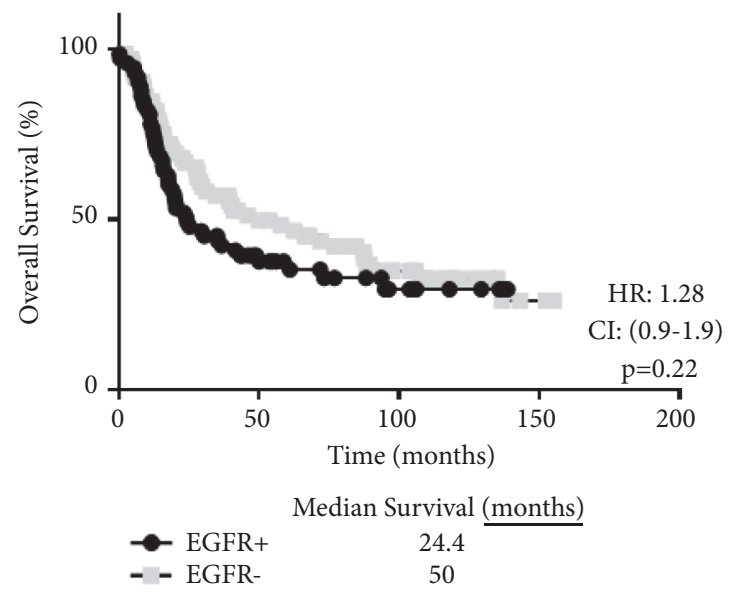

(c)

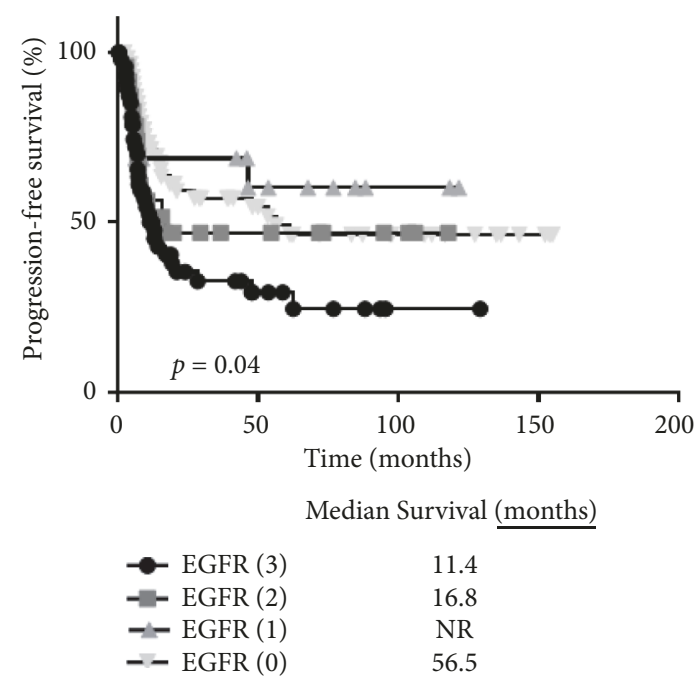

(b)

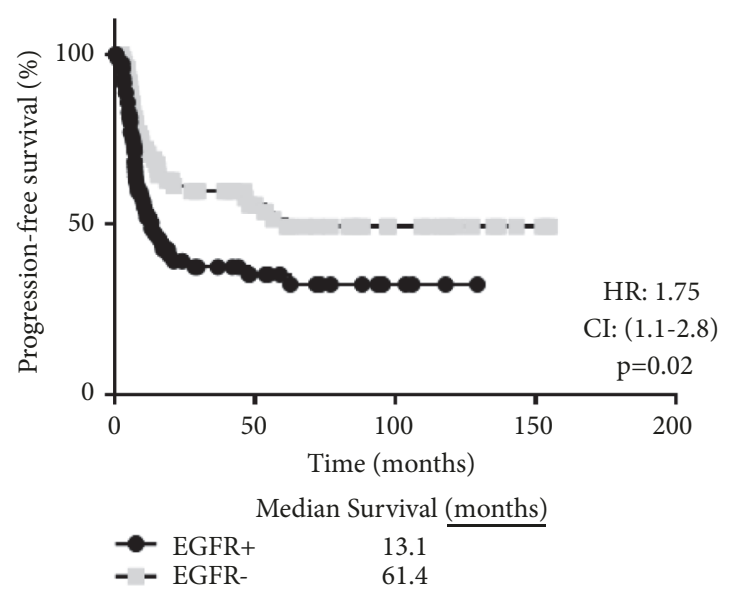

(d)

Figure 4: Prognostic impact by EGFR expression score. Shown are Kaplan-Meier estimates of overall survival (a, c) and disease-free survival $(b, d)$ according to EGFR expression score. EGFR+ and EGFR- in (c) and (d) represent combined EGFR (3) + EGFR (2) and EGFR (1) + EGFR (0) scores, respectively. NR: not reached.

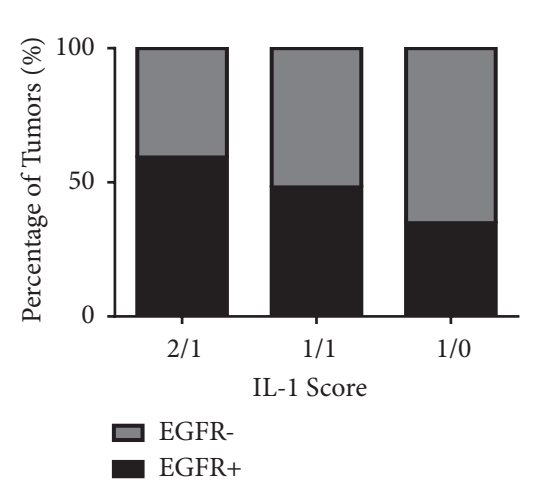

(a)

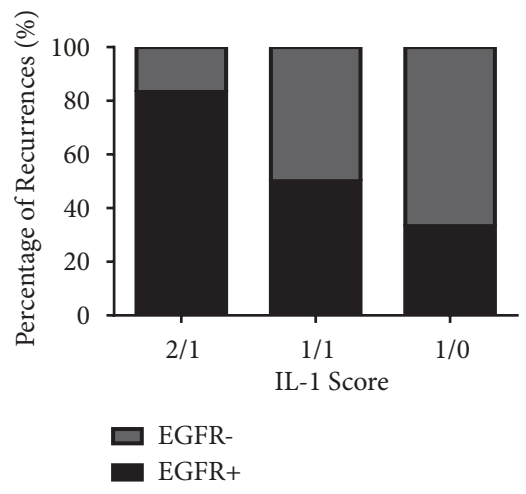

(b)

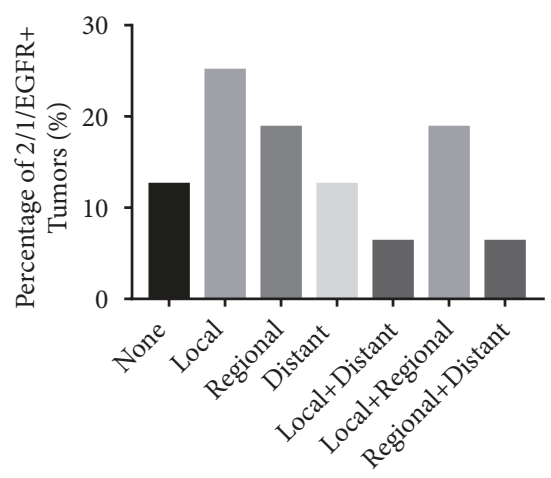

Location of Recurrences

(c)

FIGURE 5: Recurrence rates by combined EGFR/IL-1 $\alpha$ scores. Shown are the percentage of tumors (a) and percentage of tumor recurrences (b) based on combined EGFR and IL- $1 \alpha$ expression scores. Location of recurrences in 2/1/EGFR+ tumors are shown in (c). 


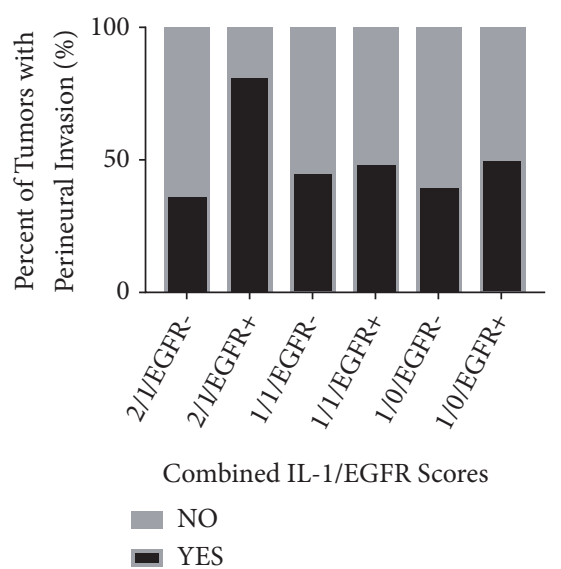

(a)

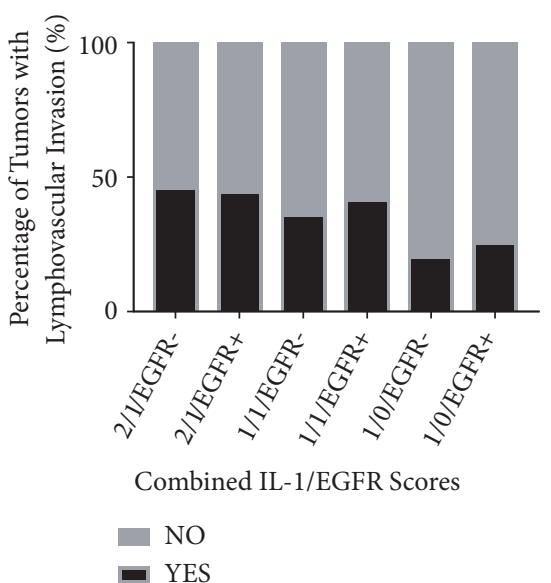

(b)

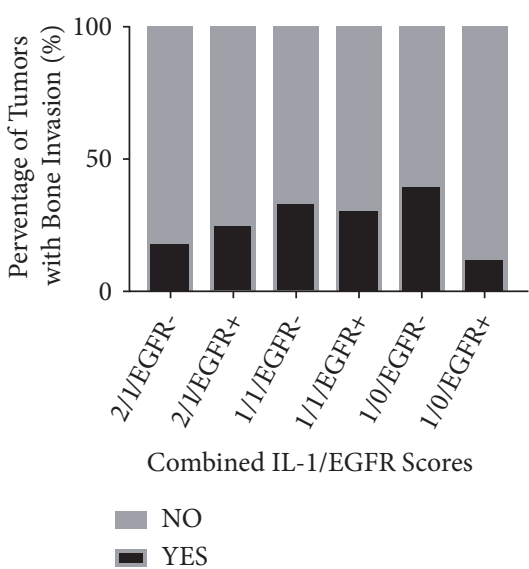

(c)

FIGURE 6: Invasion rates by combined EGFR/IL-1 $\alpha$ scores. Shown are the percentages of tumors with perineural invasion (a), lymphovascular invasion (b), and bone invasion (c) by combined EGFR and IL-1 $\alpha$ expression scores.

TABLE 2: IL-1 $\alpha$ expression scores in HNSCC tumors.

\begin{tabular}{lc}
\hline $\begin{array}{l}\text { IL- } 1 \alpha \text { Expression Scores* } \\
\text { Nuclear, cytoplasmic }\end{array}$ & $\begin{array}{c}\text { Number of Tumors } \\
(\%)\end{array}$ \\
\hline $0 / 0$ & $3(2.1)$ \\
$0 / 1$ & $4(2.8)$ \\
$1 / 0$ & $23(16.3)$ \\
$1 / 1$ & $81(57.5)$ \\
$1 / 2$ & $2(1.4)$ \\
$2 / 0$ & $1(0.7)$ \\
$2 / 1$ & $27(19.2)$ \\
\hline
\end{tabular}

*0: negative; 1 : moderate; 2 : strong

TABLE 3: EGFR expression scores in OSCC tumors.

\begin{tabular}{lcc}
\hline $\begin{array}{l}\text { EGFR } \\
\text { Expression Score } *\end{array}$ & $\begin{array}{c}\text { Number } \\
\text { of Tumors (\%) }\end{array}$ & $\begin{array}{c}\text { Number of } \\
\text { Recurrences (\%) }\end{array}$ \\
\hline 0 & $55(39)$ & $26(47)$ \\
1 & $15(11)$ & $6(40)$ \\
2 & $23(16)$ & $12(52)$ \\
3 & $48(34)$ & $31(65)$ \\
\hline
\end{tabular}

*0: negative; 1 : low; 2 : moderate; 3 : strong

gene expression, tumor cell secretion, and circulating levels of IL- $1 \alpha$ have all been associated with tumor progression and distant metastasis [5-7]. On the other hand IL-1 $\alpha$ is involved in antitumor immunity via increased natural killer (NK) cell activity, dendritic cell activity, and enhanced Th1mediated immunity [9, 27-29]. These 2 opposing properties create a controversy surrounding the potential long-term clinical effectiveness of IL-1 inhibitors for cancer therapy. The additional presence of nuclear IL- $1 \alpha$ further complicates this field since the activity of nuclear IL- $1 \alpha$ is independent of the IL-1R1. For these reasons, little/no attention has been placed on the in situ analysis of IL- $1 \alpha$ protein expression and the prognostic implications of IL- $1 \alpha$ subcellular location.
In this study we have found that IL-1 $\alpha$ is expressed in the vast majority of OSCC tumors and that IL- $1 \alpha$ is expressed in both the nuclear and cytoplasmic components (Figure 1). We observed predominant nuclear expression of IL- $1 \alpha$ since most of the IL- $1 \alpha$ expressing tumors had either nuclear only or nuclear+cytoplasmic expression (Table 2). Only 4 tumors had cytoplasmic only staining highlighting the importance of nuclear IL- $1 \alpha$ (i.e., pro-IL-1 $\alpha$ and/or IL-1 $\alpha$ propiece (ppIL$1 \alpha)$ ) in tumor cells. In support of this observation, prior studies have also shown that pro-IL- $1 \alpha$ and ppIL- $1 \alpha$ appear to be predominantly intranuclear in IL-1 $\alpha$-expressing or IL$1 \alpha$-transfected cells [30-33]. Based on the particular IL- $1 \alpha$ antibody (ab9614, Abcam) used in these studies, the nuclear IL- $1 \alpha$ detected is likely pro-IL- $1 \alpha$ and not ppIL- $1 \alpha$. To date it is not clear what role nuclear IL- $1 \alpha$ plays since some studies have reported that nuclear IL-1 $\alpha$ inhibits cell proliferation $[30,31]$ and triggers apoptosis [32]; and in other studies nuclear IL-1 $\alpha$ promotes cell proliferation [34]. It is possible that differences in experimental techniques and cell models may explain these contradicting reports. Nevertheless, we find no prognostic value in IL- $1 \alpha$ subcellular localization (Figures 2(a) and 2(b)) in this cohort of OSCC patients. However, when we take into consideration EGFR expression we found unexpected but interesting results. When separating patients from the $2 / 1,1 / 1$, and $1 / 0$ IL- $1 \alpha$-expressing groups into EGFR+ and EGFR- subgroups, we uncover a subset of tumors with a 2/1/EGFR+ profile that demonstrates significantly increased rates of perineural invasion compared to all other IL-1 $\alpha /$ EGFR expression profiles (Figure 6(a)). The presence of perineural invasion is a strong and independent predictor of local and regional failure in OSCC patients [3538]. Therefore it is no surprise that patients bearing tumors with this $2 / 1 / E G F R+$ expression profile were significantly more likely to recur compared to all of the other IL-1 $\alpha /$ EGFR expression profiles (Figure 5(b)). Patients with 2/1/EGFR+ tumors also demonstrated worse progression-free survival compared to 2/1/EGFR- tumors (Figures 7 (a) and 7(b)). This difference with EGFR expression was not observed in 1/1 


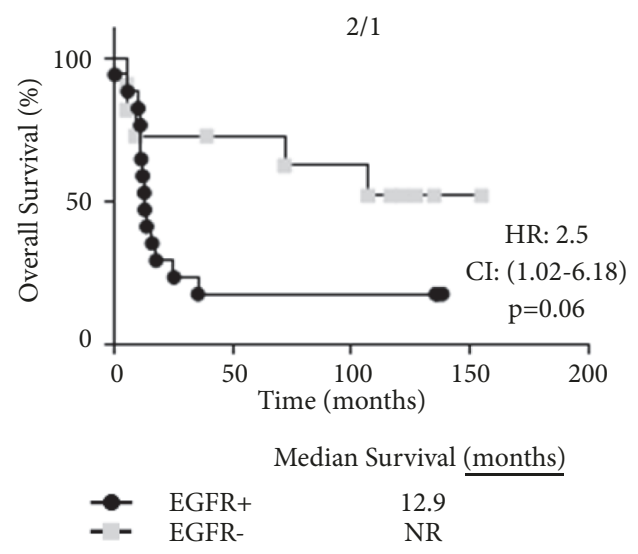

(a)

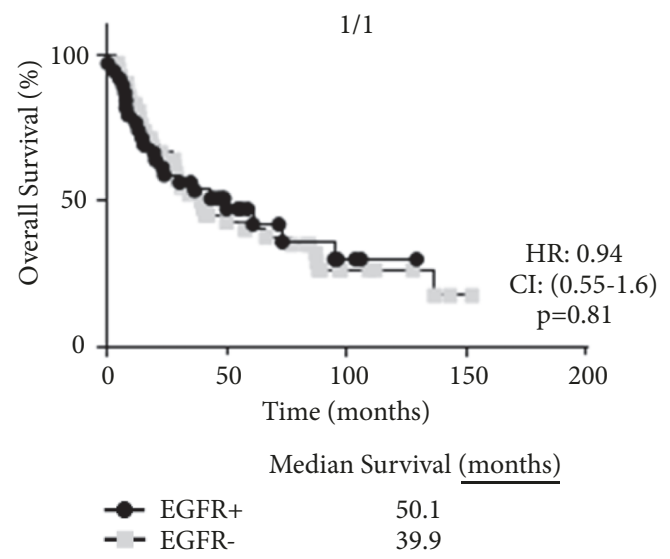

(c)

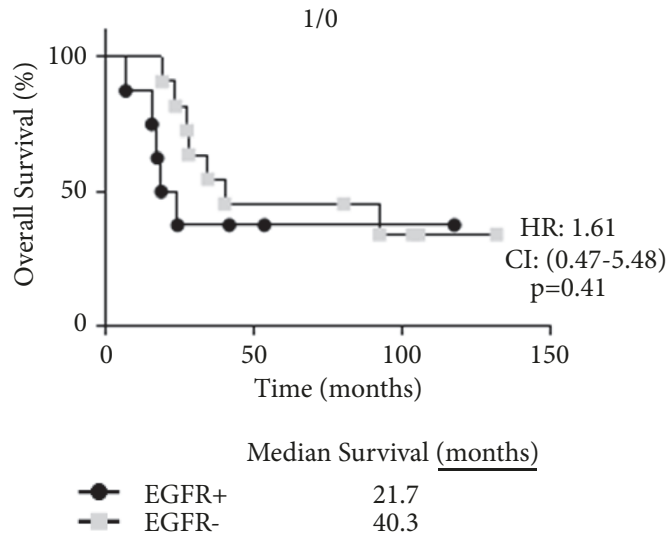

(e)

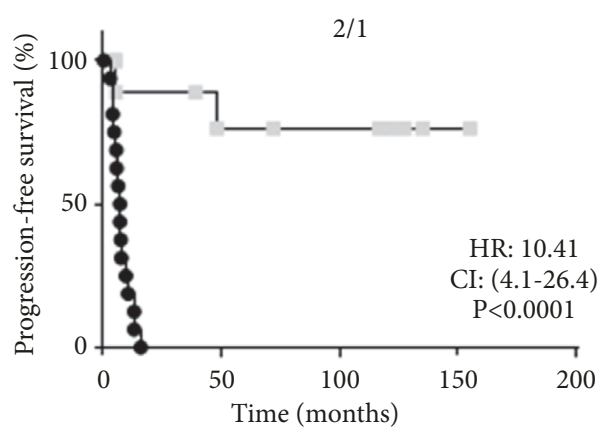

Median Survival (months)

$\bullet$ EGFR+ $\quad 7.1$

(b)

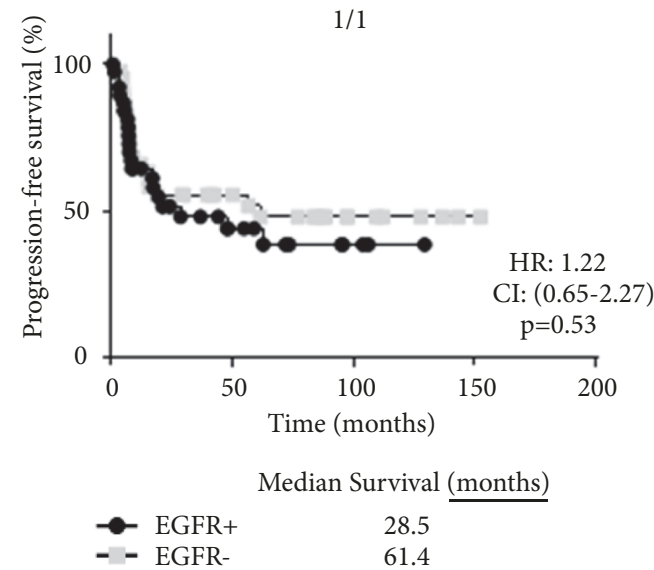

(d)

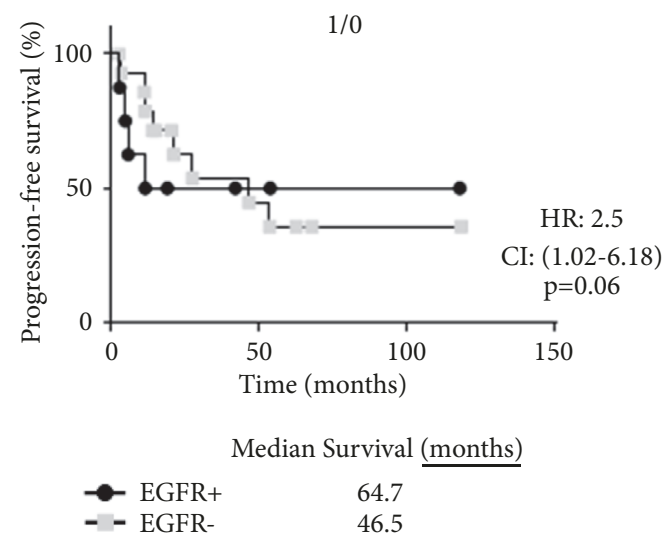

(f)

Figure 7: Prognostic impact by combined EGFR/IL-1 $\alpha$ expression scores. Shown are Kaplan-Meier estimates of overall survival (a,c,e) and progression-free survival (b,d,f) according to EGFR expression scores and 2/1 (a,b), 1/1 (c,d) and 1/0 (e,f) IL-1 $\alpha$ scores. HR: hazard ratio, CI: 95\% confidence interval. NR: not reached.

(Figures $7(\mathrm{c})$ and $7(\mathrm{~d})$ ) or $1 / 0$ (Figures $7(\mathrm{e})$ and $7(\mathrm{f})$ ) tumors suggesting a possible interaction between high nuclear IL$1 \alpha$ activity and EGFR signaling which is supported by the significant interaction $(p=0.02)$ found in Figure 5(b) between the $2 / 1$ IL-1 $\alpha$ profile score and EGFR+ expression. Of note, we found that $61 \%$ of OSCC patients with EGFR+ (score of 2 and 3) tumors experienced tumor recurrence with a median progression-free survival of 13 months (Figure 4(d)). However, if only patients with $2 / 1 / \mathrm{EGFR}+$ tumors are taken into account, 94\% of these patients experienced tumor recurrence with a median survival of 7 months (Figure 7(b)). This suggests that 2/1/EGFR-positivity may be a stronger and more accurate indicator of recurrence and progression-free survival than EGFR expression alone. 
TABLE 4: Postsurgery therapy in OSCC patients.

\begin{tabular}{lccccc}
\hline $\begin{array}{l}\text { EGFR } * / \text { IL- } 1 \alpha \\
\text { Expression Profile }\end{array}$ & $\begin{array}{c}\text { Number } \\
\text { of Patients }\end{array}$ & Chemotherapy $(\%)$ & $\begin{array}{c}\text { Radiation } \\
(\%)\end{array}$ & $\begin{array}{c}\text { Chemotherapy+Radiation } \\
(\%)\end{array}$ & P-value \\
\hline 2/1/EGFR+ & 16 & $3(19)$ & $10(63)$ & $3(19)$ & $1(9)$ \\
2/1/EGFR- & 11 & $1(9)$ & $6(55)$ & $7(18)$ & 0.19 \\
1/1/EGFR+ & 39 & $7(18)$ & $17(44)$ & $5(12)$ & 0.10 \\
1/1/EGFR- & 42 & $5(12)$ & $24(57)$ & $0(0)$ & 0.008 \\
1/0/EGFR+ & 8 & $0(0)$ & $4(50)$ & $2(13)$ & \\
1/0/EGFR- & 15 & $2(13)$ & $10(67)$ & & \\
\hline
\end{tabular}

*EGFR+: strong (3)+moderate (2) expression

EGFR-: low (1)+negative (0) expression

At this time, we are unclear as to the role of nuclear IL-1 $\alpha$ activity in EGFR signaling. Prior reports have shown that nuclear IL- $1 \alpha$ is involved in transcriptional control by interacting with the histone acetyltransferases p300, PCAF, and Gcn5 [39-41]. Transcription factors important in cancer and proinflammation pathways such as NFkB, Elk-1, C/EBP $\beta$, or AP-1 are activated by both IL-1 ligands and EGF [42]. EGFR activation has been shown to increase IL-1 ligand expression via increased $\mathrm{NFkB}$ activity in breast cancer cells resulting in increased growth and invasion [43]. Also, IL-1 ligands have been reported to transactivate EGFR through a CXCL1-CXCR2 axis [17] and ADAM17 [18] suggesting crosstalk between the EGFR and IL-1 pathways. These reports all support the synergistic interaction between the EGFR and IL-1 pathways but does not fully explain the preferential interaction of EGFR expression with nuclear IL-1 $\alpha$. Recently nuclear IL- $1 \alpha$ has been shown to increase cell proliferation in T-lymphocytic leukemia cells by binding to the promoter region of spl leading to increased spl expression and activity [15]. Sp1 is a transcription factor involved in cell growth, immune responses, and chromatin remodeling [44]. Sp1 is also involved in the regulation of numerous genes involved in invasion and metastasis [45-47]. EGFR promoter activation requires sp1 and multiple binding sites for spl have been discovered [48-50]. This suggests that high nuclear IL- $1 \alpha$ expression may promote EGFR signaling via spl activity which would explain the high recurrence rates observed in patients with 2/1/EGFR+ tumors (Figure 5(b)). Moreover, the IL- $1 \alpha$ gene has been reported to be regulated by sp1 [51, 52] suggesting a feed-forward relationship between IL-1 $\alpha$ and sp1 which would ultimately promote EGFR signaling and tumor progression. Further mechanistic studies in this area are necessary to investigate this theory.

\section{Conclusions}

Altogether, we believe we have identified a combined high nuclear IL-1 $\alpha / E G F R+$ tumor expression profile as a strong prognostic biomarker for progression-free survival in OSCC patients which warrants further study in other HNSCCs and other EGFR-expressing tumors.

\section{Data Availability}

The datasets generated during and/or analyzed during the current study are not publically available due to privacy and other restrictions but are available from the relevant authors on reasonable request.

\section{Ethical Approval}

All procedures performed in studies involving human participants were in accordance with the ethical standards of the institutional and/or national research committee and with the 1964 Helsinki Declaration and its later amendments or comparable ethical standards. For this type of study formal consent is not required. This article does not contain any studies with animals performed by any of the authors.

\section{Disclosure}

An earlier version of this study was presented as an abstract in the Experimental Biology 2019 Meeting (Abstract \# 250.2) and at the AACR 2019 Annual Meeting (Abstract \#5531).

\section{Conflicts of Interest}

The authors declare that they have no conflict of interest.

\section{Authors' Contributions}

Anand Rajan and Katherine N. Gibson-Corley contributed equally to the manuscript and they are co-first authors.

\section{Acknowledgments}

We thank the members of the Tumor Biology Group in the Department of Pathology (University of Iowa) for their helpful comments and advice on this work. We also thank the Comparative Pathology Laboratory (University of Iowa) for their expertise in generating and staining these TMAs. This work was supported by the Department of Pathology and National Institutes of Health (NIH) grants R01DE024550 and CTSA UL1TR002537 administered through the Institute for 
Clinical and Translational Science (ICTS) at the University of Iowa.

\section{References}

[1] C. A. Dinarello, "Interleukin-1 in the pathogenesis and treatment of inflammatory diseases," Blood, vol. 117, no. 14, pp. 37203732, 2011.

[2] Z. Chen, I. Colon, N. Ortiz et al., "Effects of interleukin-1alpha, interleukin-1 receptor antagonist, and neutralizing antibody on proinflammatory cytokine expression by human squamous cell carcinoma lines," Cancer Research, vol. 58, no. 16, pp. 36683676, 1998.

[3] Z. Song, Y. Lin, X. Ye et al., "Expression of IL-1 $\alpha$ and IL-6 is associated with progression and prognosis of human cervical cancer," Medical Science Monitor, vol. 22, pp. 4475-4481, 2016.

[4] G. Rodríguez-Berriguete, B. Sánchez-Espiridión, J. R. Cansino et al., "Clinical significance of both tumor and stromal expression of components of the IL- 1 and TNF- $\alpha$ signaling pathways in prostate cancer," Cytokine, vol. 64, no. 2, pp. 555-563, 2013.

[5] X. León, C. Bothe, J. García et al., "Expression of IL-lalpha correlates with distant metastasis in patients with head and neck squamous cell carcinoma," Oncotarget, vol. 6, no. 35, pp. 3739837409, 2015.

[6] A. T. Koch, L. Love-Homan, M. Espinosa-Cotton, A. Stanam, and A. L. Simons, "MyD88-dependent signaling decreases the antitumor efficacy of epidermal growth factor receptor inhibition in head and neck cancer cells," Cancer Research, vol. 75, no. 8, pp. 1657-1667, 2015.

[7] M. A. John, "Inflammatory mediators drive metastasis and drug resistance in head and neck squamous cell carcinoma," The Laryngoscope, vol. 125, supplment 3, pp. S1-S11, 2015.

[8] J. S. Wolf, Z. Chen, G. Dong et al., "IL (interleukin)-1alpha promotes nuclear factor-kappaB and AP-1-induced IL-8 expression, cell survival, and proliferation in head and neck squamous cell carcinomas," Clinical Cancer Research, vol. 7, no. 6, pp. 1812$1820,2001$.

[9] O. A. W. Haabeth, K. B. Lorvik, H. Yagita, B. Bogen, and A. Corthay, "Interleukin-1 is required for cancer eradication mediated by tumor-specific Th1 cells," OncoImmunology, vol. 5, no. 1, Article ID e1039763, 2016.

[10] D. Lin, L. Lei, Y. Liu et al., "Membrane IL1 inhibits the development of hepatocellular carcinoma via promoting $\mathrm{T}$ - and NK-cell activation," Cancer Research, vol. 76, no. 11, pp. 31793188, 2016.

[11] C. A. Dinarello, "Overview of the interleukin-1 family of ligands and receptors," Seminars in Immunology, vol. 25, no. 6, pp. 389393, 2013.

[12] B. Kim, Y. Lee, E. Kim et al., "The interleukin- $1 \alpha$ precursor is biologically active and is likely a key alarmin in the IL-1 family of cytokines," Frontiers in Immunology, vol. 4, article 391, 2013.

[13] N. M. Luheshi, N. J. Rothwell, and D. Brough, "The dynamics and mechanisms of interleukin- $1 \alpha$ and $\beta$ nuclear import," Traffic, vol. 10, no. 1, pp. 16-25, 2009.

[14] N. M. Luheshi, B. W. McColl, and D. Brough, "Nuclear retention of IL- $1 \alpha$ by necrotic cells: a mechanism to dampen sterile inflammation," European Journal of Immunology, vol. 39, no. 11, pp. 2973-2980, 2009.

[15] Y. Zhang, X. Yu, D. Lin et al., "Propiece IL-lalpha facilitates the growth of acute T-lymphocytic leukemia cells through the activation of NF-kappaB and SP1," Oncotarget, vol. 8, no. 9, pp. 15677-15688, 2017.
[16] H. Polanska, M. Raudenska, K. Hudcová et al., "Evaluation of EGFR as a prognostic and diagnostic marker for head and neck squamous cell carcinoma patients," Oncology Letters, vol. 12, no. 3, pp. 2127-2132, 2016.

[17] C.-H. Lee, S.-H. Syu, K.-J. Liu et al., "Interleukin-1 beta transactivates epidermal growth factor receptor via the CXCL1CXCR2 axis in oral cancer," Oncotarget, vol. 6, no. 36, pp. 38866-38880, 2015.

[18] E. Sanchez-Guerrero, E. Chen, M. Kockx, S.-W. An, B. H. Chong, and L. M. Khachigian, "Il-1beta signals through the egf receptor and activates egr-1 through mmp-adam," PLoS ONE, vol. 7, no. 7, Article ID e39811, 2012.

[19] R. C. Jordan, M. W. Lingen, B. Perez-Ordonez et al., "Validation of methods for oropharyngeal cancer HPV status determination in US cooperative group trials," The American Journal of Surgical Pathology, vol. 36, no. 7, pp. 945-954, 2012.

[20] A. G. Schache, T. Liloglou, J. M. Risk et al., "Evaluation of human papilloma virus diagnostic testing in oropharyngeal squamous cell carcinoma: Sensitivity, specificity, and prognostic discrimination," Clinical Cancer Research, vol. 17, no. 19, pp. 6262-6271, 2011.

[21] A. Gamboa-Dominguez, C. Dominguez-Fonseca, L. Quintanilla-Martinez et al., "Epidermal growth factor receptor expression correlates with poor survival in gastric adenocarcinoma from Mexican patients: A multivariate analysis using a standardized immunohistochemical detection system," Modern Pathology, vol. 17, no. 5, pp. 579-587, 2004.

[22] P. Bossi, C. Resteghini, N. Paielli, L. Licitra, S. Pilotti, and F. Perrone, "Prognostic and predictive value of EGFR in head and neck squamous cell carcinoma," Oncotarget, vol. 7, no. 45, pp. 74362-74379, 2016.

[23] A. Pantschenko, I. Pushkar, K. Anderson et al., "The interleukin-1 family of cytokines and receptors in human breast cancer: Implications for tumor progression," International Journal of Oncology, vol. 23, no. 2, pp. 269-284, 2003.

[24] I. Siddiqui, M. Erreni, M. A. Kamal et al., "Differential role of Interleukin-1 and Interleukin-6 in K-Ras-driven pancreatic carcinoma undergoing mesenchymal transition," OncoImmunology, vol. 7, no. 2, Article ID e1388485, 2017.

[25] A. Weber, P. Wasiliew, and M. Kracht, "Interleukin-1 (IL-1) pathway," Science Signaling, vol. 3, no. 105, Article ID cm1, 2010.

[26] Z. Zhuang, H. Ju, M. Aguilar et al., "IL1 receptor antagonist inhibits pancreatic cancer growth by abrogating NF- $\kappa \mathrm{B}$ activation," Clinical Cancer Research, vol. 22, no. 6, pp. 1432-1444, 2016.

[27] A. Eisenthal and S. A. Rosenberg, "The effect of various cytokines on the in vitro induction of antibody-dependent cellular cytotoxicity in murine cells. Enhancement of IL-2induced antibody-dependent cellular cytotoxicity activity by IL-1 and tumor necrosis factor- $\alpha$, The Journal of Immunology, vol. 142, no. 7, pp. 2307-2313, 1989.

[28] A. M. Pullyblank, P. J. Guillou, and J. R. T. Monson, "Interleukin 1 and tumour necrosis factor alpha may be responsible for the lytic mechanism during anti-tumour antibody-dependent cellmediated cytotoxicity," British Journal of Cancer, vol. 72, no. 3, pp. 601-606, 1995.

[29] A. K. Wesa and A. Galy, "IL-1 beta induces dendritic cells to produce IL-12," International Immunology, vol. 13, no. 8, pp. 1053-1061, 2001.

[30] J. A. M. Maier, M. Statuto, and G. Ragnotti, "Endogenous interleukin 1 alpha must be transported to the nucleus to exert 
its activity in human endothelial cells," Molecular and Cellular Biology, vol. 14, no. 3, pp. 1845-1851, 1994.

[31] G. Palmer, S. Trolliet, D. Talabot-Ayer, F. Mézin, D. Magne, and C. Gabay, "Pre-interleukin- $1 \alpha$ expression reduces cell growth and increases interleukin- 6 production in SaOS-2 osteosarcoma cells: Differential inhibitory effect of interleukin-1 receptor antagonist (icIL-1Ra1)," Cytokine, vol. 31, no. 2, pp. 153-160, 2005.

[32] A. S. Pollock, J. Turck, and D. H. Lovett, "The prodomain of interleukin $1 \alpha$ interacts with elements of the RNA processing apparatus and induces apoptosis in malignant cells," The FASEB Journal, vol. 17, no. 2, pp. 203-213, 2003.

[33] F. T. Stevenson, J. Turck, R. M. Locksley, and D. H. Lovett, “The N-terminal propiece of interleukin 1 alpha is a transforming nuclear oncoprotein," Proceedings of the National Acadamy of Sciences of the United States of America, vol. 94, no. 2, pp. 508513, 1997.

[34] Y. Kawaguchi, S. A. McCarthy, S. C. Watkins, and T. M. Wright, "Autocrine activation by interleukin lalpha induces the fibrogenic phenotype of systemic sclerosis fibroblasts," The Journal of Rheumatology, vol. 31, no. 10, pp. 1946-1954, 2004.

[35] S.-K. Tai, W.-Y. Li, P.-Y. Chu et al., "Risks and clinical implications of perineural invasion in T1-2 oral tongue squamous cell carcinoma," Head \& Neck, vol. 34, no. 7, pp. 994-1001, 2012.

[36] S.-K. Tai, W.-Y. Li, M.-H. Yang, P.-Y. Chu, Y.-F. Wang, and P. M.-H. Chang, "Perineural invasion as a major determinant for the aggressiveness associated with increased tumor thickness in T1-2 oral tongue and buccal squamous cell carcinoma," Annals of Surgical Oncology, vol. 20, no. 11, pp. 3568-3574, 2013.

[37] S.-K. Tai, W.-Y. Li, M.-H. Yang, P.-Y. Chu, and Y.-F. Wang, "Perineural invasion in $\mathrm{T} 1$ oral squamous cell carcinoma indicates the need for aggressive elective neck dissection," The American Journal of Surgical Pathology, vol. 37, no. 8, pp. 1164-1172, 2013.

[38] A. Tarsitano, M. L. Tardio, and C. Marchetti, "Impact of perineural invasion as independent prognostic factor for local and regional failure in oral squamous cell carcinoma," Oral Surgery, Oral Medicine, Oral Pathology, Oral Radiology, and Endodontology, vol. 119, no. 2, pp. 221-228, 2015.

[39] M. Buryskova, M. Pospisek, A. Grothey, T. Simmet, and L. Burysek, "Intracellular interleukin- $1 \alpha$ functionally interacts with histone acetyltransferase complexes," The Journal of Biological Chemistry, vol. 279, no. 6, pp. 4017-4026, 2004.

[40] A. Werman, R. Werman-Venkert, R. White et al., "The precursor form of IL- $1 \alpha$ is an intracrine proinflammatory activator of transcription," Proceedings of the National Acadamy of Sciences of the United States of America, vol. 101, no. 8, pp. 2434-2439, 2004.

[41] B. Zamostna, J. Novak, V. Vopalensky, T. Masek, L. Burysek, and M. Pospisek, "N-terminal domain of nuclear IL- $1 \alpha$ shows structural similarity to the C-terminal domain of Snfl and binds to the HAT/Core module of the SAGA complex," PLoS ONE, vol. 7, no. 8, Article ID e41801, 2012.

[42] A. Kasza, "IL-1 and EGF regulate expression of genes important in inflammation and cancer," Cytokine, vol. 62, no. 1, pp. 22-33, 2013.

[43] K. L. Streicher, N. E. Willmarth, J. Garcia, J. L. Boerner, T. G. Dewey, and S. P. Ethier, "Activation of a nuclear factor kappaB/interleukin-1 positive feedback loop by amphiregulin in human breast cancer cells," Molecular Cancer Research, vol. 5, no. 8, pp. 847-861, 2007.

[44] I. Wierstra, "Spl: emerging roles-beyond constitutive activation of TATA-less housekeeping genes," Biochemical and
Biophysical Research Communications, vol. 372, no. 1, pp. 1-13, 2008.

[45] Y. Qian, W. Yao, T. Yang et al., "aPKC-iota/P-Sp1/Snail signaling induces epithelial-mesenchymal transition and immunosuppression in cholangiocarcinoma," Hepatology, vol. 66, no. 4, pp. 1165-1182, 2017.

[46] H. Wang, K. Li, Y. Mei et al., "Sp1 suppresses miR-3178 to promote the metastasis invasion cascade via upregulation of TRIOBP," Molecular Therapy - Nucleic Acids, vol. 12, pp. 1-11, 2018.

[47] W.-H. Yen, W.-S. Ke, J.-J. Hung, T.-M. Chen, J.-S. Chen, and H. S. Sun, "Spl-mediated ectopic expression of T-cell lymphoma invasion and metastasis 2 in hepatocellular carcinoma," Cancer Medicine, vol. 5, no. 3, pp. 465-477, 2016.

[48] S. Ishii, Y. H. Xu, R. H. Stratton, B. A. Roe, G. T. Merlino, and I. Pastan, "Characterization and sequence of the promoter region of the human epidermal growth factor receptor gene," Proceedings of the National Acadamy of Sciences of the United States of America, vol. 82, no. 15, pp. 4920-4924, 1985.

[49] R. Kageyama, G. T. Merlino, and I. Pastan, "Epidermal growth factor (EGF) receptor gene transcription. Requirement for Sp1 and an EGF receptor-specific factor," The Journal of Biological Chemistry, vol. 263, no. 13, pp. 6329-6336, 1988.

[50] J. Xu, K. L. Thompson, L. B. Shephard, L. G. Hudson, and G. N. Gill, "T3 receptor suppression of Sp1-dependent transcription from the epidermal growth factor receptor promoter via overlapping DNA-binding sites," Journal of Biological Chemistry, vol. 268, no. 21, pp. 16065-16073, 1993.

[51] T. L. McDowell, J. A. Symons, and G. W. Duff, "Human interleukin- $1 \alpha$ gene expression is regulated by Spl and a transcriptional repressor," Cytokine, vol. 30, no. 4, pp. 141-153, 2005.

[52] K. Enya, H. Hayashi, T. Takii et al., "The interaction with Sp1 and reduction in the activity of histone deacetylase 1 are critical for the constitutive gene expression of IL- $1 \alpha$ in human melanoma cells," Journal of Leukocyte Biology, vol. 83, no. 1, pp. 190-199, 2008 . 


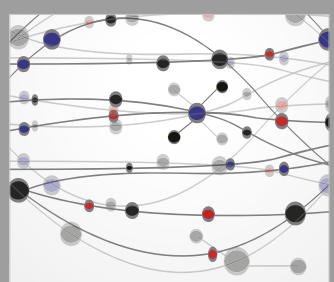

The Scientific World Journal
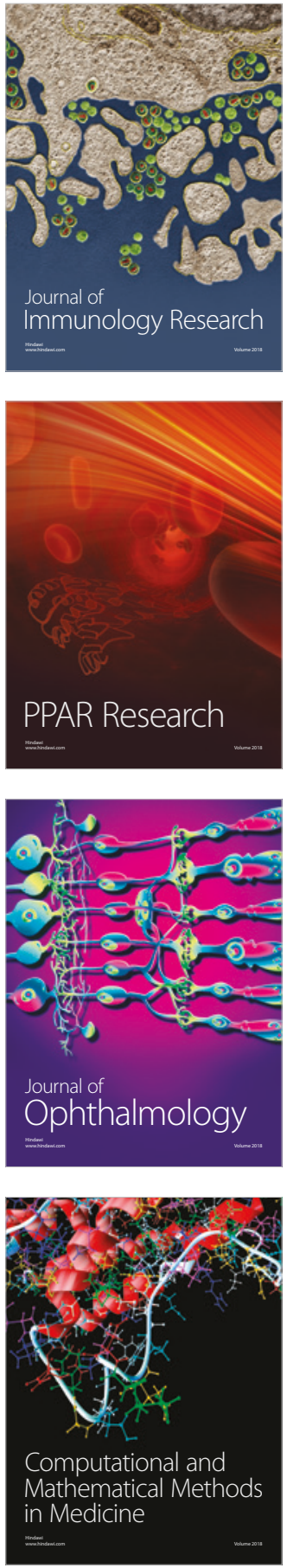

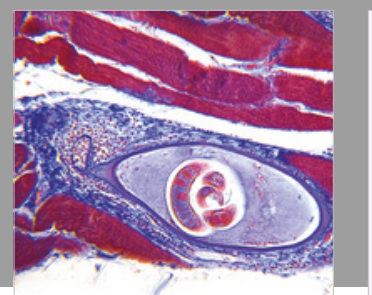

Gastroenterology Research and Practice

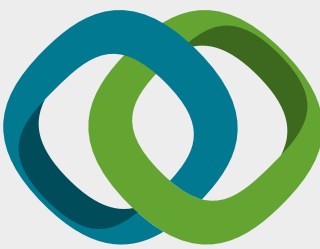

\section{Hindawi}

Submit your manuscripts at

www.hindawi.com
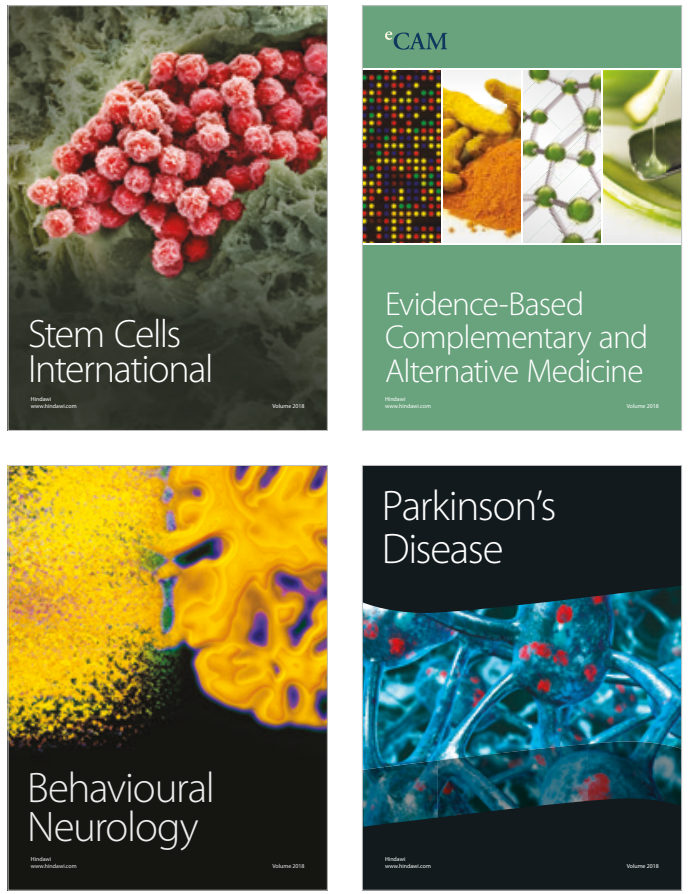

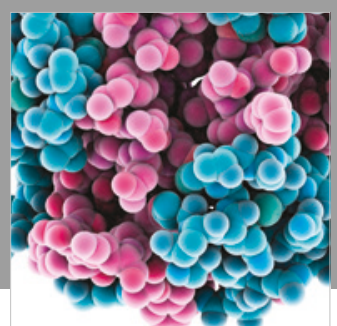

ournal of

Diabetes Research

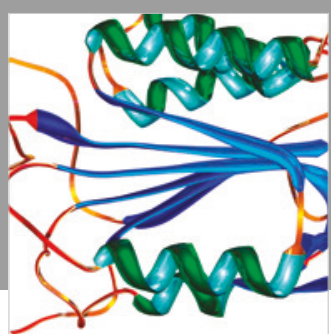

Disease Markers
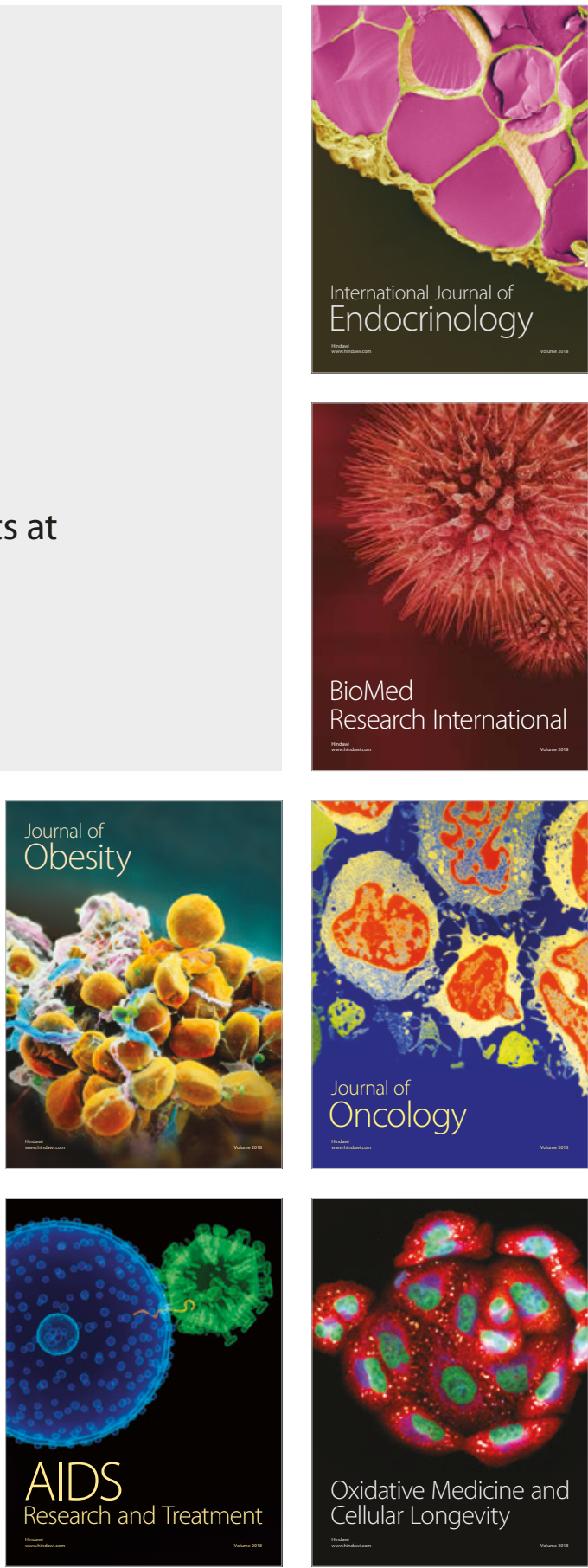